\title{
Study on the Technology of MPPT of the Solar Photovoltaic Based on the Model Predictive Control
}

\author{
Xia Zhao \\ Schoolof Electrical and Electronic Engineering \\ Shanghai Institute of Technology, Shanghai, China \\ Huailin Zhao \\ Schoolof Electrical and Electronic Engineering \\ Shanghai Institute of Technology, Shanghai, China \\ Masanori Sugisaka \\ Alife Robotics Corporation LTD, Oita, Japan \\ E-mail:zhao_huailin@yahoo.com \\ www.sit.edu.cn http://alife-robotics.co.jp/
}

\begin{abstract}
The solar photovoltaic battery is a very important new type of renewable distributed energy. But its output power is directly affected by the light intensity and temperature. Its voltage-current characteristics have obvious nonlinear features. Therefore, a new MPPT technology based on the model predictive control (MPC) is proposed in this paper. The simulation results show that the method can quickly track the maximum power point under the practical environmental conditions, and improve the energy conversion efficiency of the system.
\end{abstract}

Keywords: Photovoltaiccell; Maximum power point tracking; Solar energy; Matlab/Simulink;

\section{Introduction}

Currently the survival of humanity is inseparable from the use of energy. Along with the increasing depletion of non-renewable energy, development of renewable energy has become the theme of today's world. Solar energy as a clean and renewable energy attracts the people's attention. In some way, that photovoltaic cells convert solar energy into electricity, called photovoltaic. Because of its affection of environment and the load, and consideration of the input and output characteristics of nonlinear, this paper presents the maximum power point tracking (MPPT) principles and methods, mentions several MPPT method, and compare the advantages and disadvantages of the algorithm .

\section{Modeling the Solar Cell}

Photovoltaic cell is the device that can convert the sun light into electricity using the photovoltaic effect. The incidence of light on the cell is generates charge carrier that originate an electric current if the cell is short-circuited ${ }^{[1]}$. Basically, the PV phenomenon may be described as the absorption of solar radiation, the generation and transport of free carriers at the $p-n$ junction, and the collection of these electric charges at 
the terminals of the photovoltaic device ${ }^{[2]}$. The commonly accepted solar cell model is a one diode model ${ }^{[3]}$, which is shown in Fig. 1.This Photovoltaic cell model is a nonlinear device and can be represent as a current source model. The I-V characteristics of a photovoltaic cell is similar to diodes characteristic, and which is represent by the following equation:

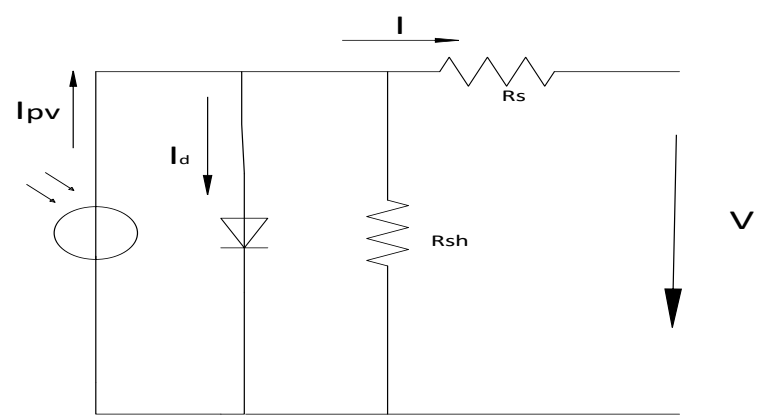

Fig.1. The circuit diagram of the photovoltaic cell

$$
I=I_{p v, c e l l}-I_{\mathrm{o}, \text { cell }}\left(\exp \left(\frac{q V}{a K T}\right)-1\right)
$$

In each array, cells connected in parallel increase current and cells connected in series provide greater output voltages. And if there have parallel connection of cells in array, the photovoltaic and saturation current can be expressed as $I_{p v}=N_{p} I_{p v, c e l l}, I_{o}=N_{p} I_{o, c e l l}$. Also the characteristic of photovoltaic arrays can be mathematically described as:

$$
I=I_{p v}-I_{O}\left\{\exp \left(\frac{q\left(V_{o}+I R_{S}\right)}{a N_{S} K T}\right)-1\right\}-\frac{V_{O}+I R}{R_{S h}}
$$

The equation (2) have a wide application in theoretical analysis of photovoltaic cell. But due to the parameters, $\mathrm{K}$, and are relative to the solar irradiance and the ambient temperature, and the value of them is hard to determined. Consider that the value of is very small, but is very large. So we can approximately see

$\left(V_{o}+I_{o} R_{s}\right) / R_{s h}$ equal to zero ${ }^{[4]}$. For the purpose of

efficiency and stability, a maximum power point tracker (MPPT) is a power electronic DC-DC converter inserted between the photovoltaic array and its load. So it ensure the photovoltaic array always works at its maximum power point as the temperature, insolation and load vary.

\section{Maximum Power Point Tracking Algorithms}

The operation of photovoltaic array are influenced by solar radiation, temperature and load values. At a given condition of irradiation and temperature, a photovoltaic cell can work at difference operation point, but there is a unique operation point of the photovoltaic array with maximum output power, that is Maximum power point (MPP). Obviously, it is necessary to take some measure to maintain the photovoltaic array work at MPP, and it also can improve the efficiency of photovoltaic power system. These measures called Maximum Power Point Tracking (MPPT) $)^{[5]}$. The principle of maximum power point tracking is through adjusting the load impedance to make the photovoltaic power generation system always work at the near maximum power point, under different environmental condition ${ }^{[6]}$.

Many research papers have produced with various schemes for the MPPT in photovoltaic power generation system. At now the commonly used method about the maximum power point tracking of photovoltaic the incremental conductance method $(\mathrm{INC})^{[7]}$, the perturbation and observation method $(\mathrm{P} \& \mathrm{O})^{[8]}$. Moreover, the fuzzy logic based method could fond in ${ }^{[9][10]}$. And the incremental conductance method (INC) and the perturbation and observation method (P\&O) are applied widely. We will discuss the incremental conductance method about MPPT algorithms in detail.

The photovoltaic cell terminal voltage can be adjusted relative to the maximum power point voltage by measuring the incremental $(d I / d V)$ and instantaneous array conductance $(I / V)$ and make use of the mentioned control strategy. It has better track of any changes either in load or photocurrent rather than the perturbation and observation method, but this way of tracking still has some oscillation which cannot be avoided. Also the simulation result of the incremental conductance algorithms will be discussed in next section.

\section{Model Predictive Control based Maximum Power Point Tracking}

As mentioned above, conventional methods to track the maximum power point the result are not as good as expected, most of them have oscillation and cannot be avoided. And this paper we consider a model predictive control based MPPT technique applied to photovoltaic module.

The main characteristic of model predictive control is predicting the future behavior of the desired control variables until a predefined horizon in time based on the present data of input or output. Also this control variables 
will be optimized by minimizing a cost function to obtain a satisfying control performance of overall system.

This paper we consider a islanded operation photovoltaic generation system as controlled member, which main consist of a photovoltaic array, a DC-DC boost converter, and a MPC controller as shown in Fig.2.

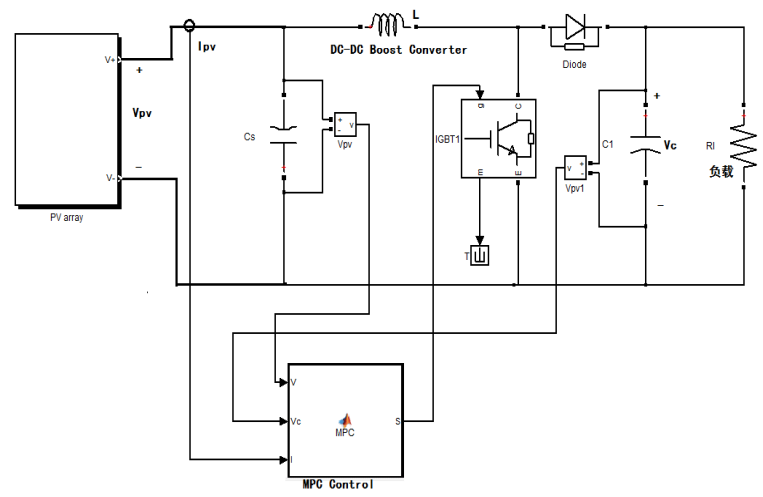

Fig.2. Control block diagram of overall islanded photovoltaic system configuration implementing MPC based MPPT technique

The photovoltaic array generates electric power directly from solar radiation. And then the power is delivered to DC load through a DC-DC boost converter, whose switch (IGBT) is operated by the MPC controller. And the states of switch are controlled by the output (S) of MPC controller. When the switch is considered as open, the equivalent circuits of the boost converter shown as Fig.3.

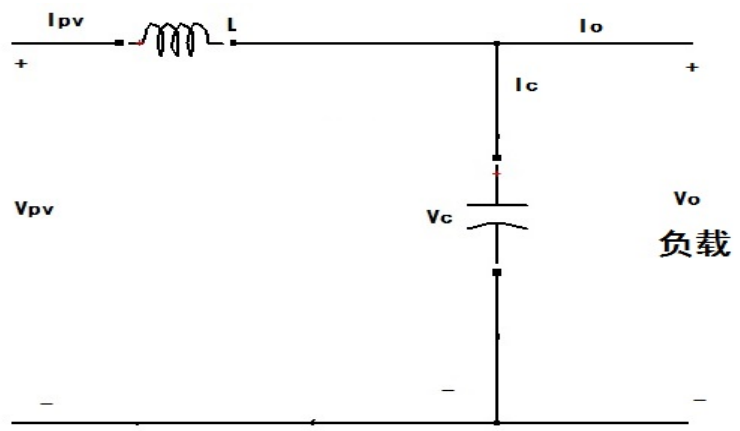

Fig.3. Equivalent circuits for boost converter when the switch is open $(\mathrm{S}=0)$

The Euler approximation is then used to obtain the discrete model of the system:

$$
\begin{gathered}
\ldots I_{p v}(k+1)=\frac{T_{s}}{L} V_{p v}(k)-\frac{T_{s}}{L} V_{C}(k)+I_{p v}(k) \\
V_{C}(k+1)=\frac{1}{C} I_{p v}(k)-\frac{1}{R C} V_{C}(k)+V_{C}(k) \\
V_{p v}(k+1)=\frac{L}{T_{s}}\left(I_{p v}(k+1)-I_{p v}(k)\right)+V_{C}(k)
\end{gathered}
$$

When the switch is closed, the equivalent circuits of the boost converter shown as Fig.4.and the equations as following:

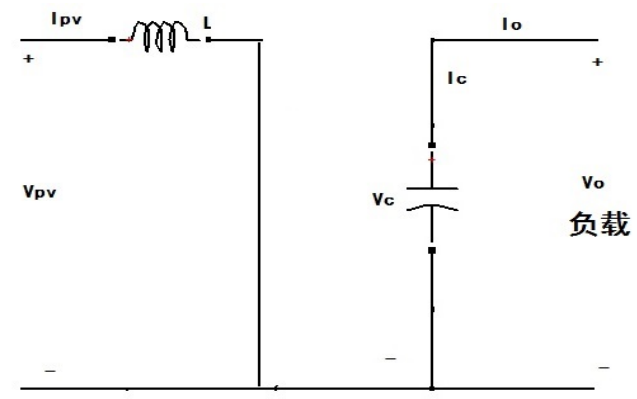

Fig.4. Equivalent circuit for boost converter when the switch is open $(\mathrm{S}=1)$

The discrete model of the system as following:

$$
\begin{gathered}
I_{p v}(k+1)=\frac{T_{s}}{L} V_{p v}(k)+I_{p v}(k) \\
V_{C}(k+1)=\left(1-\frac{T_{s}}{R C}\right) V_{C}(k) \\
V_{p v}(k+1)=\frac{L}{T_{s}}\left(I_{p v}(k+1)-I_{p v}(k)\right)
\end{gathered}
$$

Where $T_{s}$ is sampling frequency, make use of the equation (3), (4), (5) or (6), (7), (8), the behavior of the controlled variable ${ }_{p v}, V_{p v}$ and $V_{e}$ can be predicted for the next sampling instant. And we can utilize the predicted value of this control variables to distinguish whether the photovoltaic array work at the maximum power point.

\section{Simulation and Result}

In the simulation process of Solar photovoltaic cells, assuming the ambient temperature is maintained at 25 degrees, just considering the changes of the solar illumination and that three time points were given light $700{ }^{w} / m^{2}, 900{ }^{w} / m^{2}$ and $1000{ }^{w} / m^{2}$. Simulate the mutations of the light intensity at different moments with three step signal, Observe and compare the maximum 
power output tracking situation in the current environment conditions with the use of solar photovoltaic cells under the control of MPC and INC. The simulation results are shown in the following figure.

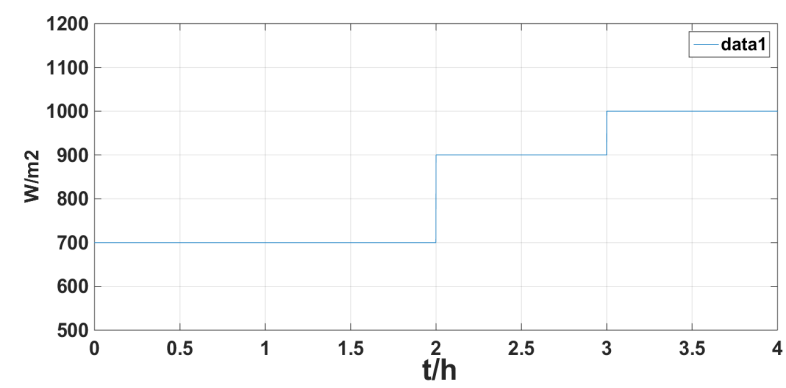

Fig,5. Light changing after time

The initial value of light was 700, at the second the light in creases by 200 , at the third second the light changed into 1000 , and the changes of the moments are mutations. Change of the light is shown in Figure 6



Fig. 6. Current changing after time

Output current is shown in Figure 7, since the output of photovoltaic solar cells is directly proportional to the light intensity of the sun, when the sunlight changes, the current of the photovoltaic cell can quickly track changes of the light.

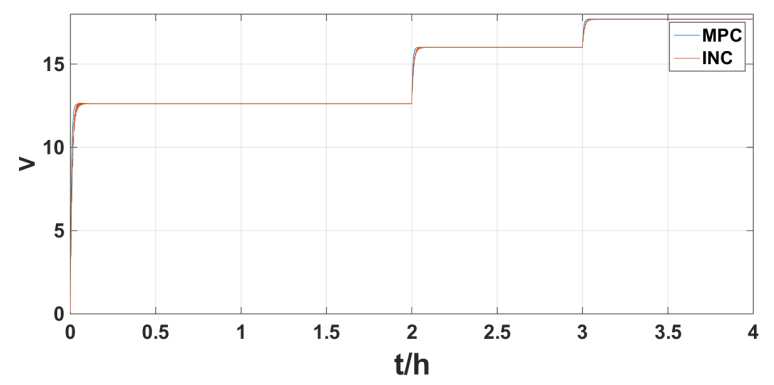

Fig.7. Voltage changing after time

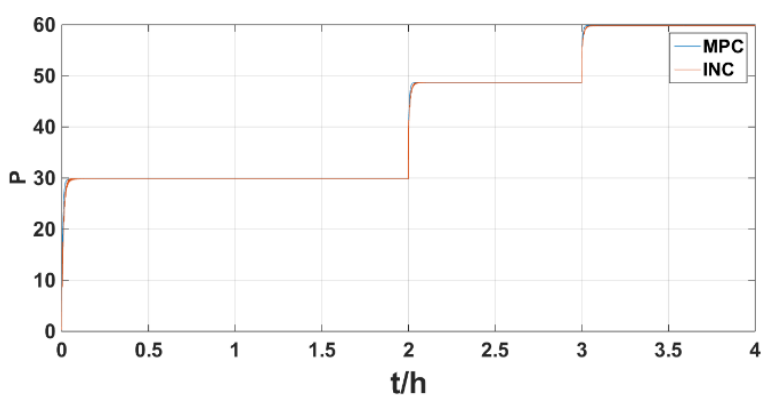

Fig.8. Output power

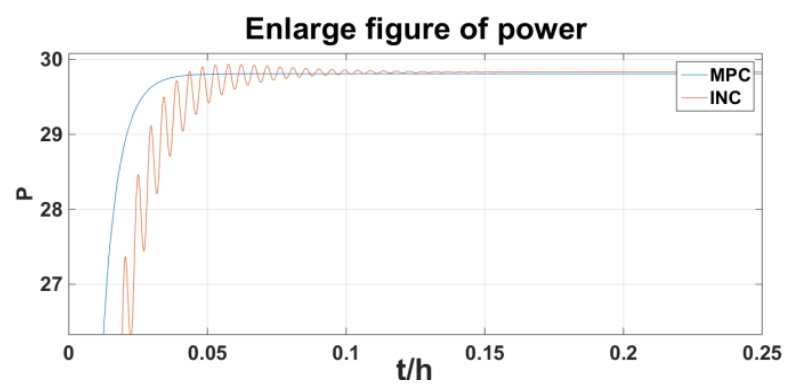

Fig.9. Zooming in on the figure of output power

Output voltage and power as respectively shown in figure 8 and figure 9. The MPC control system is no shock, and the tracking speed is significantly faster than the INC.

This paper analyzes principle under certain light intensity and ambient temperature, the output of power and operating voltage is obviously nonlinear. It is difficult to operate at the maximum outputting point of power. Therefore, in order to improve the conversion rate of solar energy, solar photovoltaic cells designed the predictive control based on the maximum power point tracking technology. The simulation shows that this method can quickly adjust the solar cell operating voltage and track the maximum power point fast, at the same time overcome the shock and other issues brought by the classic disturbance observer and incremental admittance MPPT technology.

\section{References}

1. A.Lasnier and T.G.Ang, Photovoltaic Engineering Handbook. NewYork: Adam Hilger, 1990.

2. M.G, Villava, J.R, Gazoli, and E.R, Filho, Comprehensive Approach to Modeling andSimulation of Photovoltaic Arrays [J]. Power Electronics, IEEE Transactions, 2009, Vol.24, No.5, pp.1198-1208. 
3. Geoff Walker. Evaluating MPPT Converter Topologies Using a Matlab PV Model [J].Innovation for Secure Power, Queensland University of Technology, Brisbane, Australia, 2000, PP. 138-143

4. ZENG Zhuoying and LIU Dong. Study on Cyber-Physical System Modeling on Coordinated Control of Photovoltaic Generation and Battery Energy Storage System [J]. Power System Technology, Jun/2013, Vol.37, No.6, pp.1506-1513.

5. Li Wei, Zhu Xinjian, "The Maximum Power Point Tracking Control of a Photovoltaic Power System" Computer Simulation, Vol. 23, No. 6, pp.239 243, June 2006.

6. Yang Xue; Sha Wang; Photovoltaic Cell Modeling and the Maximum Power Point Tracking Simulation; Materials for Renewable Energy and Environment (ICMREE), 2013 International Conference on; 2013, pp.119-123

7. K. H. Hussein; Maximum photovoltaic power tracking: An algorithm for rapidly changing atmospheric conditions;
Proc. Inst. Electr.Eng.-Generation, Transmission, Distribution, vol. 142, no. 1, pp. 59-64, Jan. 1995.

8. Radwan, H. ; Abdelkarem, E. ; Ahmed, M. ; Orabi, M.;The non ideality effect of optimizing the P\&O MPPT algorithm for PV battery charger applications; Telecommunications Energy Conference (INTELEC), 2011 IEEE 33rd International; 2011.

9. Anaadhakumar,G.; Venkateshkumar,M.; Shankar, P.; Intelligent controller based MPPT method for the Photovoltaic Power system; Human Computer Interactions (ICHCI), 2013 International Conference; 2013, pp.1-6.

10. Al-Mohaya; M.A.M. Mahamad, A.K.; Saon, S.; Implementation of Field Programmable Gate Array based Maximum Power Point Tracking Controller of Photovoltaic System; Power Engineering and Optimization Conference (PEOCO), 2013 IEEE 7th International; 2013, pp. 718-721. 